Article

\title{
Enhanced Oral Bioavailability of the Pharmacologically Active Lignin Magnolol via Zr-Based Metal Organic Framework Impregnation
}

\author{
Joshua H. Santos ${ }^{1,2} \mathbb{D}^{\text {, Mark Tristan J. Quimque }}{ }^{3,4}$, Allan Patrick G. Macabeo ${ }^{4}{ }^{\mathbb{D}}$, \\ Mary Jho-Anne T. Corpuz ${ }^{1,5,6}$, Yun-Ming Wang ${ }^{7}$, Tsai-Te Lu ${ }^{8}$ (D), \\ Chia-Her Lin ${ }^{9}$ and Oliver B. Villaflores ${ }^{1,2,10, *}$ \\ 1 The Graduate School, University of Santo Tomas, España Blvd., Manila 1015, Philippines; \\ jhsantos120@gmail.com (J.H.S.); mtcorpuz@ust.edu.ph (M.J.-A.T.C.) \\ 2 Phytochemistry Laboratory, Research Center for the Natural and Applied Sciences, \\ University of Santo Tomas, España Blvd., Manila 1015, Philippines \\ 3 Mindanao State University-Iligan Institute of Technology, Tibanga, Iligan City 9200, Philippines; \\ mtjquimque@gmail.com \\ 4 Laboratory for Organic Reactivity, Discovery and Synthesis (LORDS), Research Center for the Natural and \\ Applied Sciences, University of Santo Tomas, España Blvd., Manila 1015, Philippines; \\ agmacabeo@ust.edu.ph \\ 5 Pharmacology Laboratory, Research Center for the Natural and Applied Sciences, University of Santo Tomas, \\ España Blvd., Manila 1015, Philippines \\ 6 Department of Pharmacy, Faculty of Pharmacy, University of Santo Tomas, España Blvd., Manila 1015, \\ Philippines \\ 7 Department of Biological Science and Technology, Institute of Molecular Medicine and Bioengineering, \\ Center for Intelligent Drug Systems and Smart Bio-devices (IDS2B), National Chiao Tung University, \\ Hsinchu 30010, Taiwan; ymwang@mail.nctu.edu.tw \\ 8 Institute of Biomedical Engineering, National Tsing Hua University, Hsinchu 30013, Taiwan; \\ ttlu@mx.nthu.edu.tw \\ 9 College of Science, Chung Yuan Christian University, Zhongli District, Taoyuan City 320, Taiwan; \\ chiaher@gapps.ntnu.edu.tw \\ 10 Department of Biochemistry, Faculty of Pharmacy, University of Santo Tomas, España Blvd., Manila 1015, \\ Philippines \\ * Correspondence: obvillaflores@ust.edu.ph; Tel.: +63-2-8406-1611 (local 4056)
}

Received: 13 April 2020; Accepted: 5 May 2020; Published: 9 May 2020

\begin{abstract}
Bioavailability plays an important role in drug activity in the human body, as certain drug amounts should be present to elicit activity. However, low bioavailability of drugs leads to negligible use for human benefit. In this study, the diversely active neolignan, magnolol, was impregnated onto a Zr-based organometallic framework [Uio-66(Zr)] to increase its low bioavailability (4-5\%) and to test its potential acute oral toxicity. Synthesis of Uio-66(Zr) was done through the solvothermal method while simple impregnation at different time points was used to incorporate magnolol. The loading capacity of Uio-66(Zr) at $36 \mathrm{~h}$ was found to be significantly higher at $72.16 \pm 2.15 \%$ magnolol than in other incubation time. Based on the OECD 425 (limit test), toxicity was not observed at $2000 \mathrm{mg} \mathrm{kg}^{-1}$ dose of mag@Uio-66(Zr) in female Sprague Dawley rats. The area under the curve (AUC) at 0-720 min of mag@Uio-66(Zr) was significantly higher than the AUC of free magnolol. Moreover, relative bioavailability increased almost two-folds using Uio-66(Zr). Unconjugated magnolol was found in the liver, kidney, and brain of rats in all treatment groups. Collectively, Uio-66(Zr) provided a higher magnolol bioavailability when used as drug carrier. Thus, utilization of Uio-66(Zr) as drug carrier is of importance for maximal use for poorly soluble and lowly bioavailable drugs.
\end{abstract}


Keywords: magnolol; metal organic framework; bioavailability; toxicity; Uio-66(Zr)

\section{Introduction}

Despite the numerous drug compounds available, $60-70 \%$ of them are not readily soluble in aqueous media, resulting to a lower absorption rate and bioavailability [1]. Most neuroactive natural products such as magnolol, allium compounds, berberine, curcumin, genistein, ginsenoside K, and resveratrol possess low bioavailability mainly due to their poor solubility in water, low permeation, high first-pass effect and high presystemic excretion [2,3]. Magnolol, shown in Figure 1, exhibits a spectrum of biological and pharmacological activities including smooth muscle relaxation [4], inhibition of fungal and microbial growth [5], suppression of asthmatic attacks [6], interception of reactive oxygen species production [7], inhibition of cancer cell proliferation [8], and halting of inflammatory responses [9]. Similar to other natural products, the major setback in the use of magnolol as a neuroactive drug is its limited bioavailability $[10,11]$.

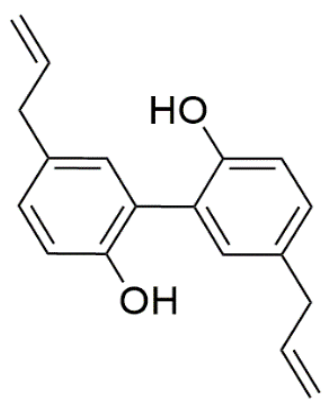

1

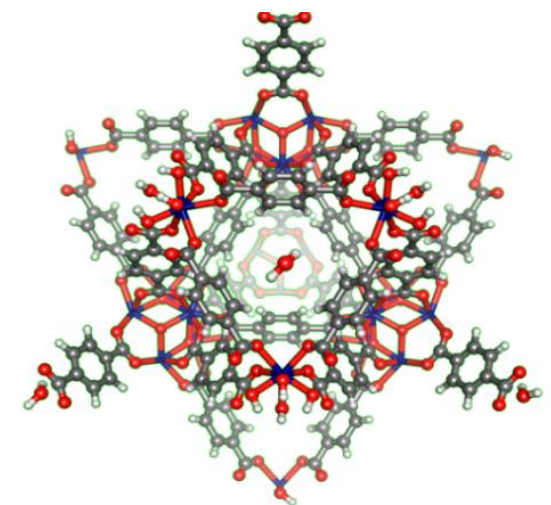

2

Figure 1. The structure of the (1) neolignan, magnolol (4-Allyl-2-(5-allyl-2-hydroxy-phenyl)phenol) and (2) Uio-66(Zr). (as visualized using ACD/Chemsketch ver 2018.1, Canada).

Approaches to increase the bioavailability of magnolol include the use of micellar particles [12,13], mesoporous silica [14], nanoparticles [15,16], solid dispersions [17,18], and liposomes [19]. As part of our continuing efforts to increase the bioavailability of biologically active natural products with limited solubility in aqueous systems, a metal organic framework (MOF) was utilized in this study as drug delivery system for crystalline yellow magnolol (1). MOFs are porous coordination networks [20] or coordination polymers [21] composed of a central metal ion and organic linkers. MOFs are characterized to have high porosity, thermal stability, discrete ordered structure, ultra-low density, large internal surface area (above $6000 \mathrm{~m}^{2} \mathrm{~g}^{-1}$ ), ease of synthesis, and various applications. MOFs also possess high degree of crystallinity and order of units [22]. These characteristics through a potential pocket enable MOFs to facilitate entry and binding of drugs (guest molecules) [23]. In this study, a zirconium-based MOF Uio-66(Zr), was found to have high porosity, shear, and thermal stability [24]. Zirconium and its complexes exhibit low systemic toxicity resulting from its poor water solubility [25-27]. Several studies revealed that Uio-66(Zr) (2) can be used as a drug carrier system for anticancer [28,29], anti-inflammatory [30], and antibacterial agents [31]. It was also able to enter cells via clathrin-mediated endocytosis [27].

In this paper, we performed a solvothermal method for Uio-66(Zr) synthesis and the simple impregnation technique to incorporate magnolol. Pure Uio-66(Zr) and mag@Uio-66(Zr) were characterized and compared to assess magnolol impregnation by thermogravimetric analysis (TGA), powder X-ray diffraction (PXRD), and nitrogen sorption isothermal techniques. Our study reports for 
the first time the preparation of a magnolol-loaded metal organic framework based on zirconium with increased oral bioavailability.

\section{Materials and Methods}

\subsection{Material and Reagents}

Magnolol ( $\geq 98 \%$ ) was purchased from Xi'an Lyphar Biotech Co., LTD. (Xi'an, China). Zirconium chloride $\left(\mathrm{ZrCl}_{4}, 99.9 \%\right)$, and trifluoroacetic acid (TFA, 99\%) were purchased from Alfa Aesar, Inc. (Shanghai, China). Terephthalic acid (98\%) used in this study was purchased from Tokyo Chemical Industry Co., LTD. (Kumagaya, Saitama, Japan). Dimethylformamide, anhydrous (DMF, 99.8\%) was purchased from Merck LTD. (Taipei, Taiwan). Acetonitrile, HPLC grade (99.9\%), and hydrochloric acid ( $\mathrm{HCl}, 35.5-38.1 \%)$ was purchased from JT Baker (Phillipsburg, NJ, USA). Ethanol (95\%) was purchased from Tianjin Jingming Chemical Co., LTD. (Tianjin, China). Ultrapure water used was prepared from with Milli-Q ultrawater system. All reagents were used without further purification.

\subsection{Animals}

Female non-nulliparous Sprague Dawley (SD) rats (300 $\pm 50 \mathrm{~g})$ and male SD rats (200 $\pm 50 \mathrm{~g})$ were purchased from Laboratory Animal Facility, Research \& Biotechnology Group, St. Luke's Medical Center (Manila, Philippines). All rats were provided distilled water ad libitum. The animals were housed at controlled temperature of $25 \pm 2{ }^{\circ} \mathrm{C}$ and relative humidity of $45 \pm 5 \%$ for 7 days prior to experimentation. All animal experiments were reviewed and approved by the Institutional Animal Care and Use Committee (IACUC) of the University of Santo Tomas (AR-2017-352, dated 21 September 2017). Prior to dosing, animals were fasted for $12 \mathrm{~h}$ and were only given distilled water.

\subsection{Methods}

\subsubsection{Synthesis of Uio-66(Zr)}

$\mathrm{UiO}-66(\mathrm{Zr})(2)$ was synthesized using the solvothermal method as previously described by Ahmed et al. (2016) [32]. Two millimoles of $\mathrm{ZrCl}_{4}$ and $4 \mathrm{mM}$ of terephthalic acid were dissolved in $50 \mathrm{~mL}$ of

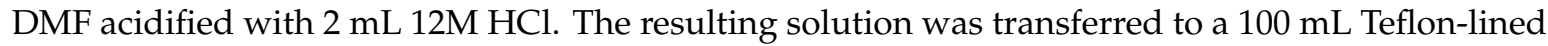
autoclave and was heated at $180^{\circ} \mathrm{C}$ for $24 \mathrm{~h}$. The MOF powder was filtered and washed with DMF ( $1 \mathrm{~g}$ of MOF: $50 \mathrm{~mL}$ DMF). The residue was dried at $150{ }^{\circ} \mathrm{C}$ for $5 \mathrm{~h}$. The solution was centrifuged at $5000 \mathrm{rpm}$ for $10 \mathrm{~min}$, the supernatant liquid was discarded, and the powder was dried for $12 \mathrm{~h}$ in vacuum oven at $150{ }^{\circ} \mathrm{C}$.

Activation was done by washing the MOF with 95\% ethanol (10 mg MOF: $1 \mathrm{~mL}$ ethanol). The mixture was agitated using a vortex mixer for $30 \mathrm{~min}$. The resulting solution was centrifuged at $10,000 \mathrm{rpm}$ for $5 \mathrm{~min}$ to separate the powder and supernatant liquid. The procedure was repeated 5 times and the obtained MOFs were dried at $110^{\circ} \mathrm{C}$ vacuum oven for $24 \mathrm{~h}$ [33].

\subsubsection{Magnolol Impregnation and Quantification}

Magnolol (1) was loaded into the Uio-66(Zr) framework through simple impregnation. In particular, $1 \mathrm{mg}$ of Uio-66(Zr) was mixed with $100 \mu \mathrm{L}$ of magnolol solution $(20 \mathrm{mg} / \mathrm{mL}$ in ethanol) at $75 \mathrm{rpm}$ in a closed tube, resulting in a 1:2 (Uio-66(Zr):magnolol) ratio. The mixture was mixed for 12, 24, 36, and $48 \mathrm{~h}$. The mixture was centrifuged at 10,000 rpm for $5 \mathrm{~min}$ to separate the supernatant liquid and MOF. Addition of $200 \mu \mathrm{L}$ of ethanol was done with careful pipette in-out to remove the magnolol adhered outside the Uio-66(Zr) and the container. The mixture was recentrifuged again to separate the washing and MOF. The washing was combined with the previously collected supernatant liquid and kept for subsequent analysis. The collected MOF was labeled as Mag@Uio-66(Zr). The amount of magnolol loaded into the MOF was determined indirectly by measuring the amount of unentrapped magnolol in the combined washing and supernatant liquid [14,34]. 
The amount of magnolol impregnated into the MOF was determined by detecting the amount of free magnolol present in the supernatant liquid by using the high performance liquid chromatography method using HPLC Agilent 1100 series with Luna $5 \mu \mathrm{m}$ C18(20) 100 angstrom, 250 mm $\times$ $4.6 \mathrm{~mm}$ (H15-216693) equipped with UV-VIS diode array detector (Agilent Technologies, Germany). Acetonitrile and water with $0.1 \%$ trifluoroacetic acid (80:20) were used as mobile phases [14,35].

$$
\text { Drug Loading Percent }=\frac{T A-S A}{T A} \times 100
$$

where TA—total amount of magnolol in solution (mg); $S A$-amount of magnolol in supernatant (mg).

\subsubsection{Characterization of Magnolol-Loaded MOF}

Nitrogen Sorption Isotherms

Samples were outgassed under high vacuum at 60 degrees for $48 \mathrm{~h}$ to remove the residual solvents attached in the MOF using the Quantachrome Nova 2200 instrument and pore size surface area analyzer (Anton Paar QuantaTec Inc., Taipei, Taiwan). The Brunauer-Emmett-Teller (BET) specific surface area $\left(S_{B E T}\left(\mathrm{~m}^{2} / \mathrm{g}\right)\right)$ was calculated from the linear part of the BET plot.

\section{Thermogravimetric Analysis}

Samples (10-20 mg) were placed into the ceramic pans and heat from $50{ }^{\circ} \mathrm{C}$ to $800{ }^{\circ} \mathrm{C}$ with a heat rate of $10^{\circ} \mathrm{C} / \mathrm{min}$ under nitrogen atmosphere $(20 \mathrm{~mL} / \mathrm{min})$. Temperature vs. percent weight loss was graphed to determine the change between the loaded and unloaded MOF.

\section{Powder X-ray Diffraction (PXRD)}

X-ray Diffraction patterns of the unloaded and loaded MOF were compared to confirm the presence of magnolol in the particle. The patterns were determined at $30 \mathrm{kV}$ and $10 \mathrm{~mA}$ with monochromated $\mathrm{Cu} \mathrm{K} \alpha$ radiation and a scan speed of $0.5-3.5 \mathrm{~s} / \mathrm{step}$ and a step size of $0.03^{\circ}$. Two thetas were determined at $5^{\circ}$ to $50^{\circ}$ using D2 Phase Bruker (Bruker, Taiwan) [36].

\section{Scanning Electron Microscopy (SEM)}

Samples were dried under vacuum and mounted into carbon double adhesive tape. The samples were coated with platinum under argon atmosphere and reduced pressure to increase the conductivity of the sample. The analysis was done at 5000 to 100,000 magnifications with 10,000 accelerating voltage using field emission scanning electron microscopy (JSM-7600F) (JEOL, Hsinchu, Taiwan). Micropictographs were obtained for every sample.

\section{Particle Size Determination}

Samples were diluted with ultrapure water with a refractive index of 1.33 at $25^{\circ} \mathrm{C}$ and 78.304 dielectric constant to make $1000 \mathrm{ppm}$ concentration and sonicated for $10 \mathrm{~min}$ at $40 \mathrm{kHz}$ to facilitate distribution of the particles. Particle size was determined using the dynamic light scattering method (Nanoplus 1, Micromeritics Particulate Systems) (GatScientific Sdn Bhd, Selangor, Malaysia).

\subsubsection{In Vitro Drug Release}

Mag@Uio-66(Zr) was subjected to the in vitro drug release study using sample and separate method [37]. Approximately $20 \mathrm{mg}$ of MOF carrier containing magnolol was submerged into $20 \mathrm{~mL}$ release media (0.1 $\mathrm{M}$ hydrochloric acid ( $\mathrm{pH} 2.0$ ), $1.0 \mathrm{M}$ phosphate buffered saline $\mathrm{pH} 7.4$ and 6.8) confined in sealed $20 \mathrm{~mL}$ capacity glass vials maintained at $37 \pm 0.5^{\circ} \mathrm{C}$ with a constant stirring at a rate of around $75 \mathrm{rpm}$. An aliquot amount of $100 \mu \mathrm{L}$ was taken during 0.5, 1, 2, 3, and $4 \mathrm{~h}$ time interval. A fresh amount of release media was used to compensate for the amount of release media taken every 
time points. The aliquot was assayed to determine the amount of magnolol released throughout the experiment using the HPLC method described above. The release percent of magnolol was calculated according to the following equation: percent magnolol release $=\{$ (actual amount of magnolol/loaded amount of magnolol) $\times 100\}$ [35].

The cumulative released amount of magnolol from the MOF was utilized to predict and correlate the behavior of the in vitro release. The experimental data were fitted to five predictable models: zero-order, first-order, Higuchi, Korsmeyer-Peppas, and Hixson-Crowell models [38]. Data fitting was performed by linear regression using Microsoft Excel. The correlation coefficient $\left(\mathrm{r}^{2}\right)$ was utilized in the criterion for selecting the best model that describes the release profile in the three media. The value of $\mathrm{r}^{2}$ closes to 1 signifies the best correlation.

\subsubsection{Acute Oral Toxicity}

Animal toxicity test was done in accordance with the Organization for Economic Cooperation and Development guidelines for testing chemical compounds using the up and down method (OECD procedure 425). Prior to dosing, $2 \mathrm{~mL}$ of blood was extracted through tail clipping and was submitted for alanine aminotransferase (ALT) and creatinine level determinations for signs of liver and kidney damages, respectively. A dose of $2000 \mathrm{mg} \mathrm{kg}^{-1}$ was administered to a single female SD rat through oral gavage and was observed for $24 \mathrm{~h}$ for signs of toxicity and death. In cases where the first animal survived, an additional four rats were subjected to the same dose. A total of 5 test animals were observed in a 14 days period for signs of toxicity and death. An additional rat was administered with the solvent only to compare the variation in the animal species. Test animals that survived in the 14-day observation were euthanized in a carbon dioxide chamber followed by the harvesting of blood, liver and kidney of all test animals. The blood was once again submitted for ALT and creatinine level determination. The organs were submitted for tissue mounting and histopathological evaluation [39].

\subsubsection{Oral Bioavailability and Tissue Distribution}

The determination of the bioavailability of magnolol and its tissue distribution to the brain, liver, and kidney was done according to the method of Ding et al. (2018), Higashi (2015), Lin et al. (2011), and Kotani et al. (2005) [13,40-42].

\section{Collection of Serum Samples}

For the pharmacokinetic study, male SD rats were randomly divided into 4 groups $(n=3)$. In particular, 2 groups were given magnolol at a dose of $100 \mathrm{mg} \mathrm{kg}^{-1}$ via oral and intraperitoneal routes; another set of two groups was given the same dose of mag@Uio-66(Zr). Blood samples (approximately 200 to $250 \mu \mathrm{L}$ ) were collected at predetermined time points $(15,30,60,120,180,240$, 480 , and $720 \mathrm{~min}$ ) and allowed to clot and centrifuged at $4000 \mathrm{rpm}$ at $4{ }^{\circ} \mathrm{C}$ for $5 \mathrm{~min}$ to obtain the serum. The obtained sera were treated with equal amount of acetonitrile and then centrifuged again to obtain the protein-free sera.

\section{Collection of Tissue Samples}

For the tissue distribution study, male SD rats were divided into two groups $(n=3)$ and were given either magnolol or mag@Uio-66(Zr) orally administered at a dose of $50 \mathrm{mg} \mathrm{kg}^{-1}$. After one hour of administration, the animals were euthanized in a carbon dioxide chamber and their organs (brain, liver, and kidney) were collected. The organs were weighed and homogenized in $10 \mathrm{~mL}$ of acetonitrile, and centrifuged at 10,000 rpm for $10 \mathrm{~min}$. The supernatant was dried under reduced pressure.

\section{Magnolol Quantification}

Samples were reconstituted with acetonitrile prior to HPLC analysis. The samples were injected into the HPLC $(n=3)$. The quantity of magnolol was computed using a standard calibration curve. 


\subsubsection{Statistical Analysis}

All experiments were conducted triplicates. Statistical analysis of significance was performed using the SPSS 19.0 statistical software (SPSS Inc., Chicago, IL, USA). Differences within the group were evaluated using paired sample t-test, while differences between various groups were evaluated using one-way analysis of variance (ANOVA), and $p$-value $<0.05$ indicated statistical significance. Post hoc analysis was done using Tukey HSD.

\section{Results}

\subsection{Magnolol Impregnation and Quantification}

The crystalline yellow magnolol (1) was impregnated to Uio-66(Zr) (2) and the residual magnolol was quantified using HPLC. Upon complete impregnation of magnolol, a color change was observed from white [pure Uio-66(Zr)] to slightly yellow [mag@Uio-66(Zr)] powder. This color change is due to the presence of excess magnolol. The mean drug loading efficiencies at four-time points depicted significant differences $(p<0.001)$. In particular, the mean drug loading efficiency at $36 \mathrm{~h}$ time point is significantly greater compared to other three time points $(p<0.001)$, as shown in Figure 2 . A time-dependent drug loading efficiency of Uio-66(Zr) was observed until the 36th hour $(24.86 \pm 2.43 \%$ $<28.64 \pm 1.59 \%<72.16 \pm 2.15 \%)$. However, efficiency drastically decreased after $48 \mathrm{~h}(19.51 \pm 6.85 \%)$.

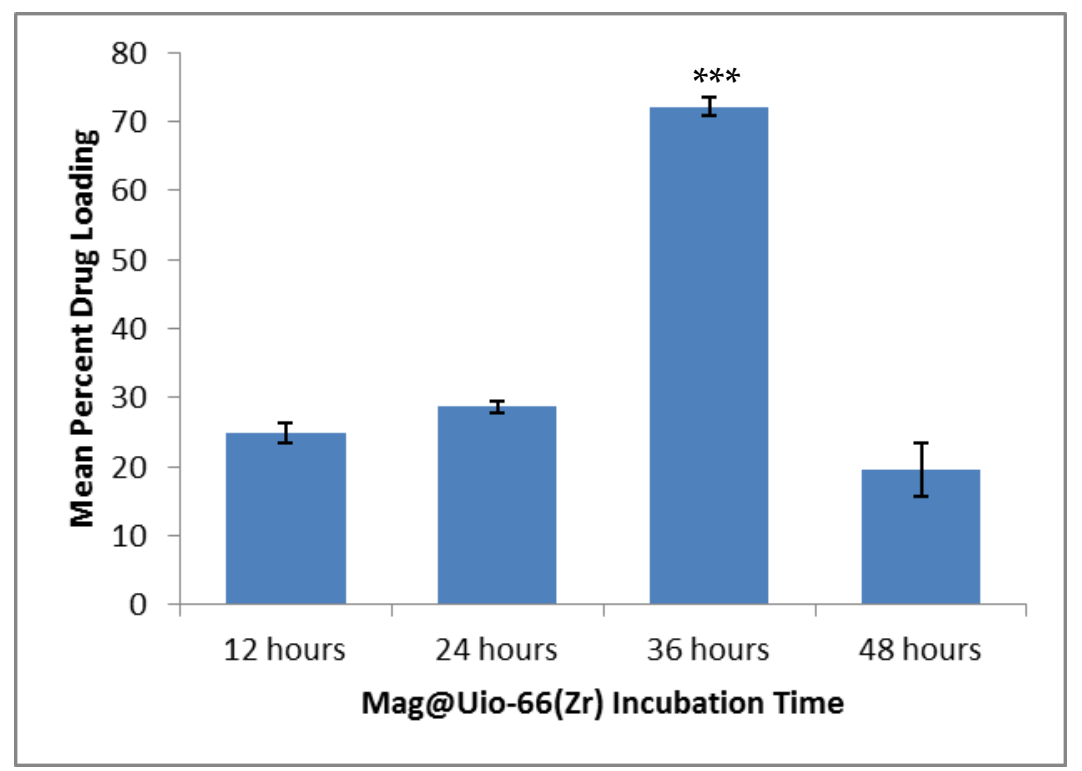

Figure 2. Mean drug loading efficiency of magnolol at four different time points. $n=3$. Data presented as mean \pm S.E.M.; ${ }^{* * *}$ significant difference at $0.05 p$-value.

\subsection{Characterization of mag@Uio-66(Zr)}

\subsubsection{Nitrogen Sorption Isotherms}

Nitrogen adsorption-desorption isotherms were obtained and analyzed to determine the Brunauer-Emmett-Teller (BET) surface areas of the pure Uio-66(Zr) and mag@Uio-66(Zr) at the 36 th hour incubation time. This was done to check if magnolol was successfully impregnated to Uio-66(Zr) as determined by a decrease in surface area in the MOF. Thus, a decrease in BET surface area, pore volume and pore diameter of the pure Uio-66(Zr) upon incorporation of magnolol were observed. The following changes in pore and surface properties were noted: BET surface area (from $1156.0643 \mathrm{~m}^{2} / \mathrm{g}$ to $951.9567 \mathrm{~m}^{2} / \mathrm{g}$ ), pore volume (from $0.473321 \mathrm{~cm}^{3} / \mathrm{g}$ to $0.380273 \mathrm{~cm}^{3} / \mathrm{g}$ ), and pore diameter (from $16.37 \AA$ to $15.97 \AA$ ). The reduction in parameters after drug incorporation is attributed 
on the impregnation of magnolol in the Uio-66(Zr) framework. A sharp increase in the nitrogen adsorption at low pressure was noted, indicating the void space in the pristine framework. Overlapping of the adsorption-desorption isotherms in Uio-66( $\mathrm{Zr}$ ) at low pressure indicates a microporous structure, as shown in Figure 3A [35].

\subsubsection{Thermogravimetric Analysis (TGA)}

Thermal degradation of Uio-66(Zr) and mag@Uio-66(Zr) was studied through TGA to check the incorporation of magnolol in the MOF framework. Pure Uio-66(Zr) was stable up to $560^{\circ} \mathrm{C}$ as shown in Figure 3B, while two thermal degradations were noted in the mag@Uio-66(Zr) thermogram. The first was attributed to the impregnated magnolol at $350-400{ }^{\circ} \mathrm{C}$, while the second thermal degradation at $\sim 560^{\circ} \mathrm{C}$ was due to Uio-66(Zr). Shifts in the thermogram curve of the loaded and unloaded Uio- $66(\mathrm{Zr})$ exhibit differences in thermal property which may be corroborated to magnolol impregnation in the MOF structure [43-45]. In addition, based on the relative percentage weight of mag@Uio-66(Zr), as seen in the thermogram curve in Figure 3B, there is a lower residual mass due to higher organic material (magnolol and terephthalate) lost during the course of analysis.

\subsubsection{Powder X-ray Diffraction (PXRD)}

The crystalline integrity of Uio-66(Zr) conforming to the simulated crystalline structure and the integrity after incorporation of Uio-66(Zr) with magnolol was determined using PXRD, as shown in Figure 3C. The PXRD spectrum for the synthesized Uio-66(Zr) was identical to that of the simulated spectral patterns obtained from validated single crystal structure of Uio-66(Zr), indicating successful formation, crystallinity and phase homogeneity, as displayed in Figure 3C. The structural integrity of Uio-66(Zr) remained even after impregnation with magnolol at $36 \mathrm{~h}$ indicated by no change in PXRD spectral patterns between unloaded MOFs and loaded MOFs. These findings indicate the stability of mag@Uio-66(Zr) up to $36 \mathrm{~h}$. Additionally, the level and intensity of the peaks were significantly reduced after exposure to magnolol. These changes with the PXRD spectral patterns were attributed to the incorporation of magnolol within the Uio-66(Zr) structure [35]. Furthermore, the absence of Bragg peaks corresponding to free magnolol rules out the presence of free recrystallized magnolol outside of the pores of the material [46].

\subsubsection{Scanning Electron Microscopy (SEM)}

SEM was done to determine the microcrystallinity and textural shapes of pure Uio-66(Zr) and mag@Uio-66(Zr). Figure 3D,E shows the nature of microcrystallinity and relatively similar textural shape of the unloaded and loaded Uio-66(Zr). Uio-66(Zr) and corresponding loaded one display a quasi-spherical or nearly spherical shape.

\subsubsection{Particle Size Determination}

Particle sizes of the Uio-66(Zr) and mag@Uio-66(Zr) were determined. Significant increase in the particle size of Uio-66( $\mathrm{Zr})$ after loading was also noted with sizes of $338.90 \mathrm{~nm} \pm 18.42 \mathrm{~nm}$ and $500.80 \pm 16.63 \mathrm{~nm}$, respectively $(p=0.012)$. The increase in the particle size could be due to the loading of magnolol. 

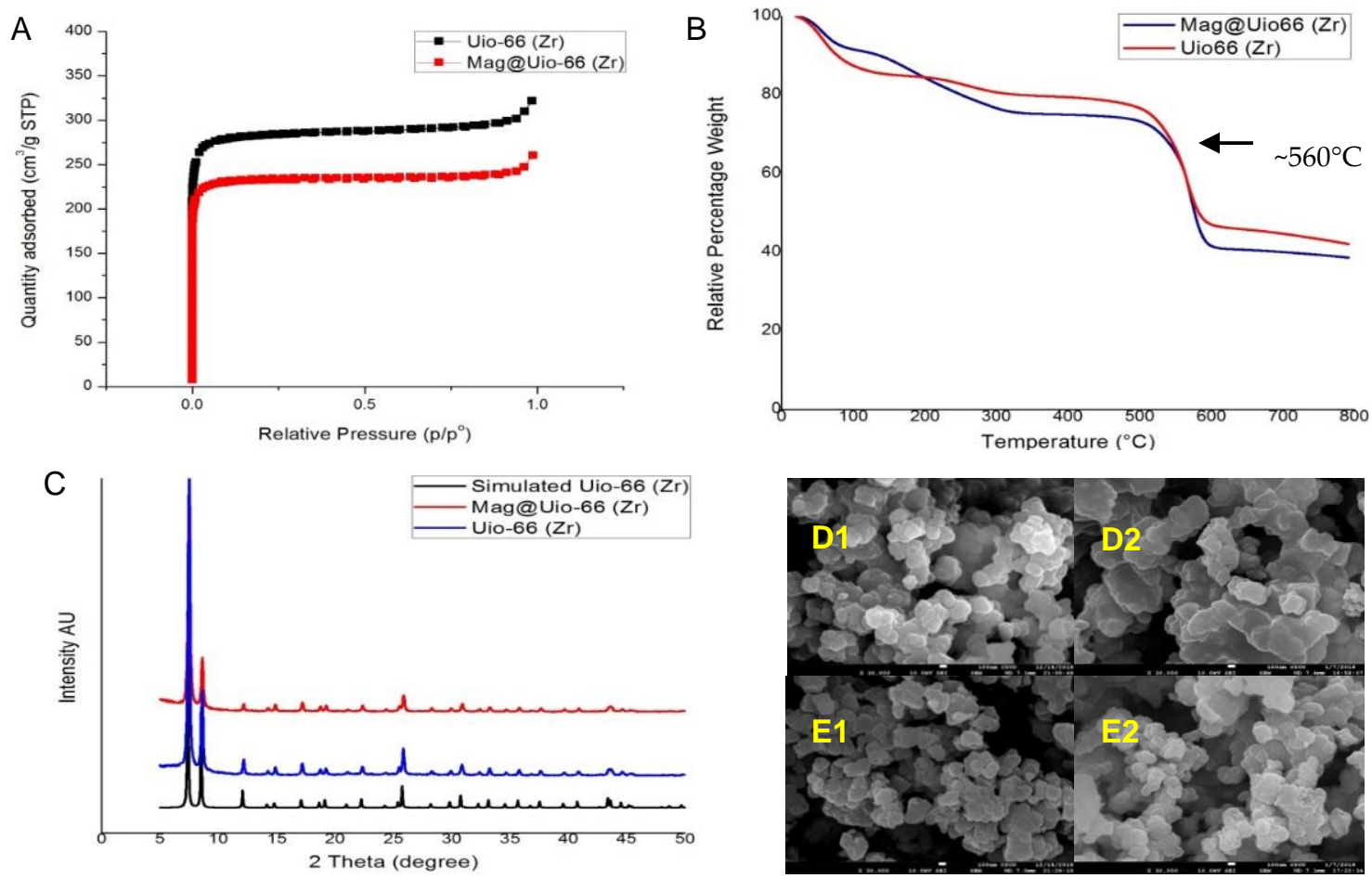

Figure 3. Characterization of pure Uio-66(Zr) and mag@Uio-66(Zr) after 36 h. (A) nitrogen adsorption-desorption plot, (B) thermogram plot, (C) XRD pattern, (D1-2) micropictograph of pristine Uio-66(Zr) at 30,000×, and (E1-2) micropictograph of mag@Uio-66(Zr) at 30,000×.

\subsection{In Vitro Drug Release}

In vitro drug release of the mag@Uio-66(Zr) prepared after $36 \mathrm{~h}$ was carried out at $1.0 \mathrm{M}$ phosphate buffered saline (PBS) at $\mathrm{pH} 7.4$ (simulated blood $\mathrm{pH}$ ) and $\mathrm{pH} 6.8$ (simulated intestinal $\mathrm{pH}$ ), and $0.1 \mathrm{M}$ hydrochloric acid pH 2.0 (simulated gastric $\mathrm{pH}$ ), as shown in Figure 4. The drug release experiment was carried out for four hours. After four hours of drug release, the cumulative percentage of magnolol released were $2.47 \pm 0.37 \%$ (PBS pH 6.8), $2.89 \pm 0.09 \%$ (PBS pH 7.4), and $4.19 \pm 0.03 \%(0.1 \mathrm{M} \mathrm{HCl} \mathrm{pH}$ 2 ). With these cumulative values of magnolol released, it was deduced that there was a very slow release of magnolol in the simulated release media. The data were plotted to determine the release kinetic profile at zero order kinetics, first order kinetics, Higuchi model, Korsmeyer-Peppas model and Hixson Crowell model (refer to Table S1 for regression factors $\left(\mathrm{r}^{2}\right)$ of all five models).

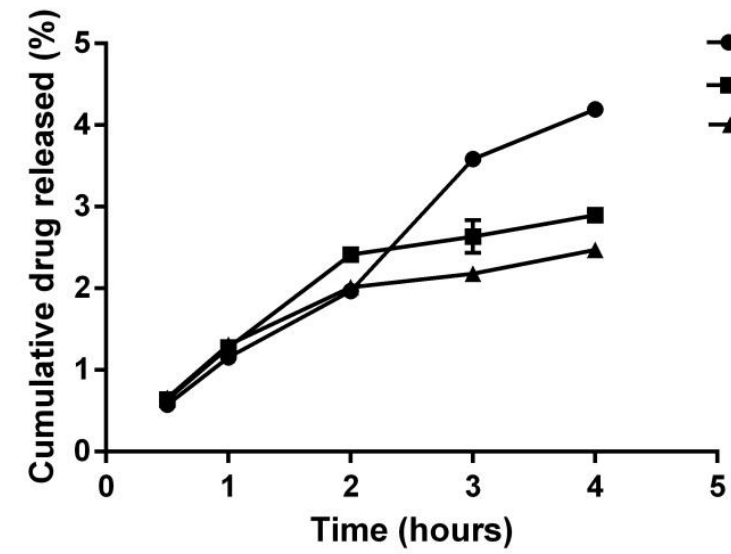

Figure 4. Cumulative drug release of magnolol from mag@Uio-66(Zr) in three media. $\mathrm{HCl}$-hydrochloric acid; PBS-phosphate buffered saline at pH 7.4 and 6.8. 


\subsection{Acute Oral Toxicity}

Acute oral toxicity was performed to check the preliminary toxicity of magnolol and mag@Uio-66(Zr) based on the Organization for Economic Cooperation and Development guidelines for testing chemical compounds using the up-and-down method (OECD procedure 425). All test animals survived the $2000 \mathrm{mg} \mathrm{kg}^{-1}$ limit dose after oral administration of both magnolol and mag@Uio-66(Zr). Therefore, the median lethal dose $\left(\mathrm{LD}_{50}\right)$ for both magnolol and mag@Uio-66(Zr) were assumed to be greater than $2000 \mathrm{mg} \mathrm{kg}^{-1}$. To validate the result, serum (alanine transaminase) ALT and creatinine levels for magnolol- and mag@Uio-66(Zr)-treated groups were taken before and after administration of the test sample, as displayed in Figure 5. Using paired t-test analysis, the mean serum ALT level for both magnolol and mag@Uio-66(Zr) groups displayed no significant difference $(p=0.276$ and $p=0.055$, respectively). Interestingly, the magnolol-treated group showed a significantly lowered serum creatinine levels after oral administration $(p=0.440)$ while no significant difference in the mean serum creatinine levels for mag@Uio-66(Zr)-treated group $(p=0.446)$ was observed. The control test animal, receiving only the vehicle, exhibited no significant differences for both serum ALT and creatinine levels ( $p=0.330$ and $p=0.500$, respectively). Interestingly, the toxicity evaluation of mag@Uio-66(Zr) had produced neither deaths nor signs of toxicity.
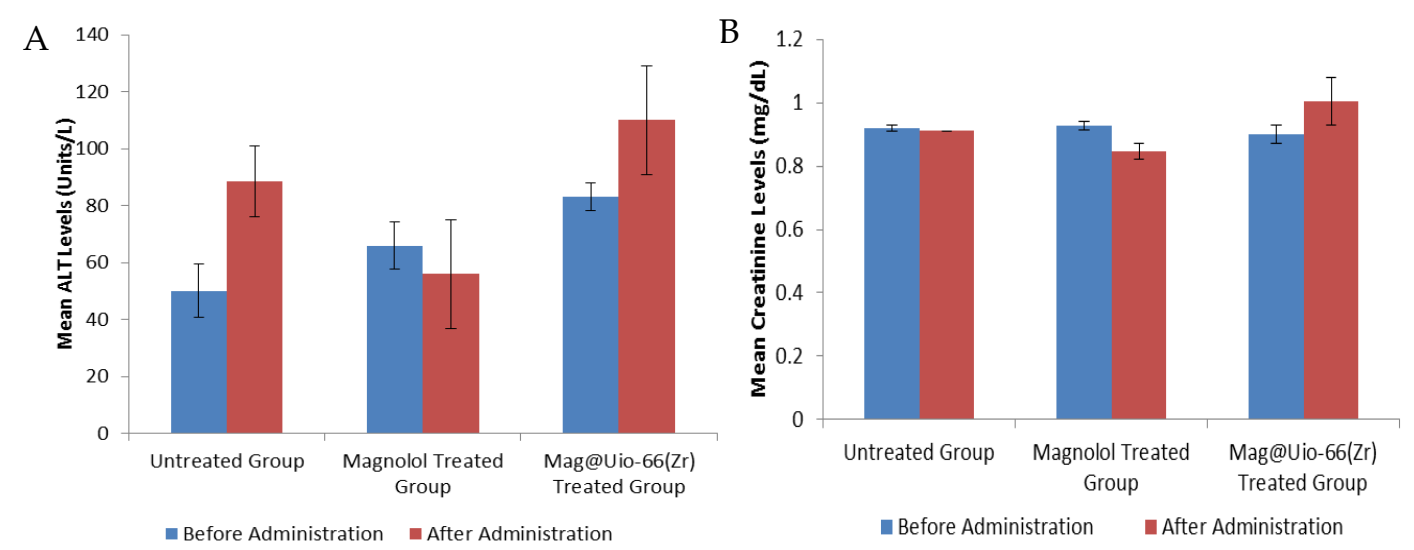

Figure 5. Serological parameter for acute oral toxicity. (A) mean ALT levels (units/L) for magnolol and mag@Uio-66(Zr) treated group, and $(\mathbf{B})$ mean creatinine $(\mathrm{mg} / \mathrm{dL})$ levels for magnolol and mag@Uio-66(Zr) treated group. Blood extraction was done before and after administration of test compounds. $n=5$. Data presented as mean \pm S.E.M.

Gross necropsy revealed no signs of macroscopic damage on both livers and kidneys of the test animals. Histopathological evaluation of the liver and kidney tissue slides was done to check microscopic damages. Regional hepatocytes with the limiting plates were seen intact for all sections of the liver sample, as shown in Figure 6. Observed mild hepatocyte atrophy was only related to the general nutrition and unrelated to the test compound. Granularity and swelling of the hepatocyte cytoplasm were within limits. For all sections of kidneys shown in Figure 7, no pathological damages were observed on the glomeruli and proximal tubular epithelia. Occasional cast formations on some tubules were observed but not of significant magnitude. 

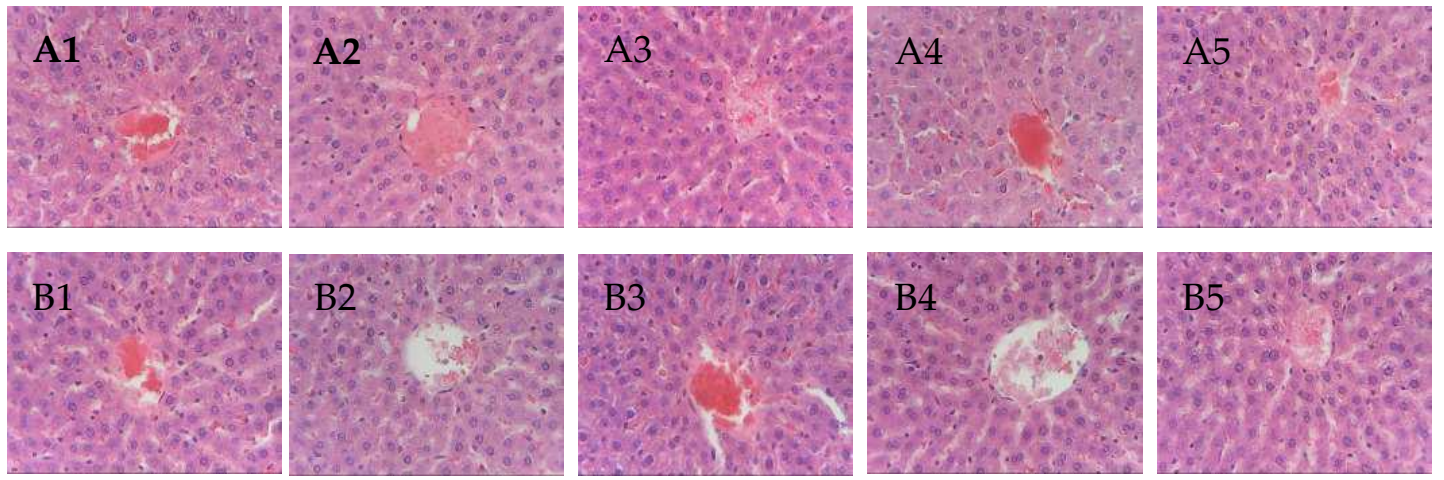

Figure 6. Micropictograph of the liver tissue sections for (A) magnolol treated group (from left to right, rat 1 to 5), and (B) mag@Uio-66(Zr)treated group (from left to right, rat 1 to 5).

Samples were stained with hematoxylin and eosin dyes. Micropictograph was taken at the periacinar hepatocyte using 40X objective in an OlympusCH2 microscope fitted with a $5 \mathrm{MP}$ camera.
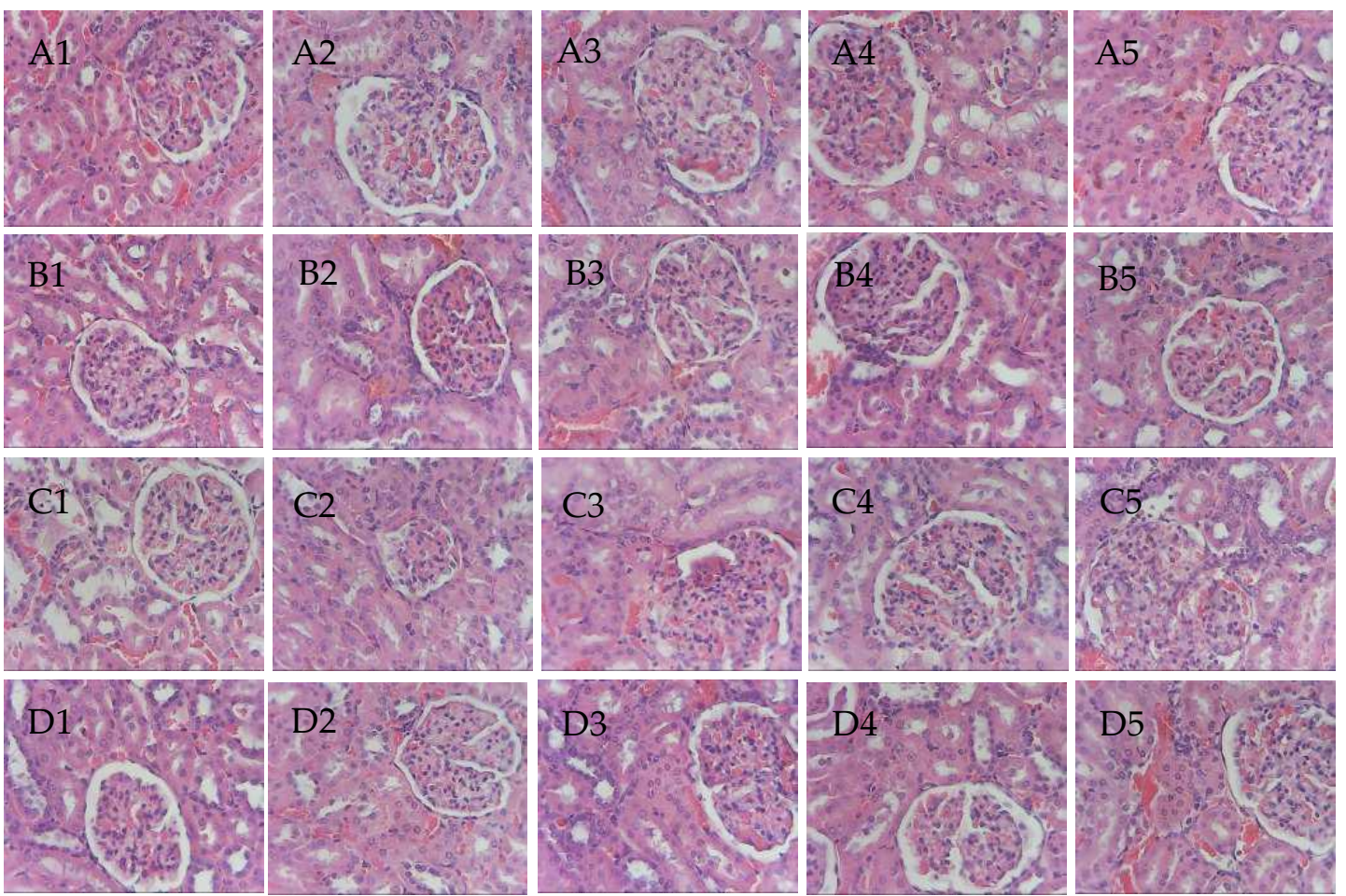

Figure 7. Micropictograph of the kidney tissue sections for(A) right kidney (magnolol treated group), (B) left kidney (magnolol treated group), (C) right kidney (mag@Uio-66(Zr) treated group), and (D) left kidney (mag@Uio-66(Zr) treated group) (from left to right, rat 1 to 5).

Samples were stained with hematoxylin and eosin dyes. Micropictograph was taken at the glomeruli and proximal tubule using $40 \times$ objective in OlympusCH2 microscope fitted with a 5MP camera.

\subsection{Oral Bioavailability and Tissue Distribution}

\subsubsection{Oral Bioavailability}

Oral bioavailability of magnolol was determined by administering pure magnolol and mag@Uio-66(Zr). The pharmacokinetic parameters of magnolol and mag@Uio-66(Zr) are shown in 
Table 1. Figure 8 shows the mean plasma concentration-time curve of magnolol in rats following either oral or intraperitoneal administration of $100 \mathrm{mg} \mathrm{kg}^{-1}$ of magnolol and mag@Uio-66(Zr). To have insights on the plasma concentration of magnolol present in a certain amount of time, and to show systemic exposure to magnolol, the area under the curve (AUC) was determined [47]. The area under the curve from time 0 to $720 \mathrm{~min}\left(\mathrm{AUC}_{0-720}\right)$ of mag@Uio-66(Zr) is significantly higher than the $\mathrm{AUC}_{0-720}$ of magnolol-treated group ( $p=0.010$ ) at post oral administration, as shown in Figure 8A. Meanwhile, the $\mathrm{AUC}_{0-720}$ between magnolol and mag@Uio-66(Zr) after intraperitoneal route administration depicted no significant difference $(p=0.412)$, as displayed in Figure $8 \mathrm{~B}$. Comparing $\mathrm{AUC}_{0-720}$ between oral and intraperitoneal administration of pure magnolol showed a significant difference $(p<0.001)$ wherein the intraperitoneal route of administration possesses greater $\mathrm{AUC}_{0-720}$, as shown in Figure $8 \mathrm{C}$. Interestingly, the $\mathrm{AUC}_{0-720}$ between the oral and intraperitoneal route of mag@Uio-66(Zr) showed no significant difference $(p=0.182)$, as shown in Figure 8D. This indicates the promising use of Uio-66(Zr) as drug carrier for magnolol as indicated by enhancement in $\mathrm{AUC}_{0-720}$ which is also considered comparable to the intraperitoneal route.
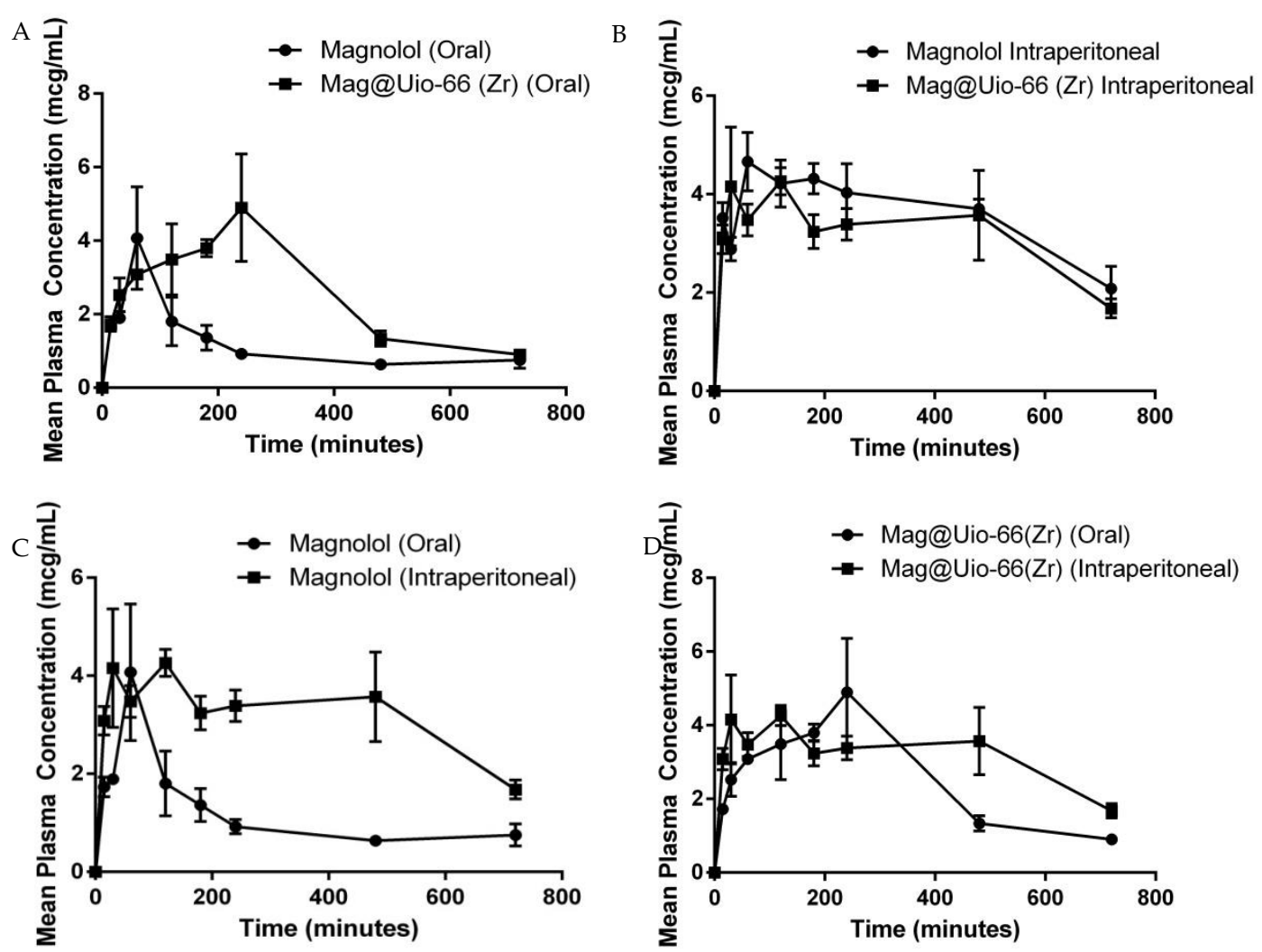

Figure 8. Area under the curve $\left(\mathrm{AUC}_{0-720}\right)$ graph of (A) magnolol (oral) and mag@Uio-66(Zr) (oral), (B) magnolol (intraperitoneal) and mag@Uio-66(Zr) (intraperitoneal), (C) magnolol (oral) and magnolol (intraperitoneal), and (D) mag@Uio-66(Zr) (oral) and mag@Uio-66(Zr) (intraperitoneal). $n=3$. Data plotted as mean \pm S.E.M. in time (minutes) and mean plasma concentration of magnolol $(\mu \mathrm{g} / \mathrm{mL})$. 
Table 1. Summary of the pharmacokinetic parameters for oral and intraperitoneal route of magnolol and mag@Uio-66(Zr).

\begin{tabular}{|c|c|c|c|c|c|c|}
\hline \multirow{2}{*}{ Test Compound } & \multicolumn{6}{|c|}{ Parameters } \\
\hline & $\mathrm{AUC}_{0-720}(\mu \mathrm{g} / \mathrm{mL} \mathrm{min})$ & $\mathrm{AUC}_{0-\infty}(\mu \mathrm{g} / \mathrm{mL} \min )$ & $\operatorname{Tmax}(\min )$ & $\mathrm{Cmax}(\mu \mathrm{g} / \mathrm{mL})$ & $\mathrm{T}_{1 / 2}(\min )$ & $\operatorname{Abs} T_{1 / 2}(\min )$ \\
\hline Magnolol PO & $823.3 \pm 139.10$ & $903.97 \pm 140.09$ & $55.77 \pm 4.17$ & $2.57 \pm 0.26$ & $100 \pm 20.40$ & $23.26 \pm 3.16$ \\
\hline Mag@Uio-66(Zr) PO & $1823 \pm 167.31$ * & $2099.95 \pm 148.48$ * & $196.97 \pm 17.38^{*}$ & $3.77 \pm 0.33 *$ & $206.21 \pm 27.95 *$ & $118.92 \pm 6.22 *$ \\
\hline Magnolol IP & $2582.67 \pm 150.48$ & $4016.90 \pm 535.62$ & $64.06 \pm 6.88$ & $5.10 \pm 0.65$ & $460.88 \pm 37.41$ & $17.14 \pm 3.63$ \\
\hline Mag@Uio-66(Zr) IP & $2312.67 \pm 253.76$ & $3831.72 \pm 451.57$ & $114.27 \pm 7.09^{* *}$ & $5.65 \pm 2.41$ & $606.35 \pm 114.37$ & $33.26 \pm 4.09 * *$ \\
\hline
\end{tabular}

$n=3$; Data presented as mean \pm S.E.M. * significant difference between oral route at $95 \%$ confidence interval; ** significant difference between intraperitoneal route at $95 \%$ confidence interval; $\mathrm{PO}-$ oral route; IP-intraperitoneal route; $\mathrm{AUC}_{0-720}$-area under the curve from 0 to $720 \mathrm{~min} ; \mathrm{Cmax}$-maximal plasma concentration; Tmax-maximal time reaching the maximal plasma concentration; $\mathrm{T}_{1 / 2}$ - elimination half-life; $\mathrm{Abs}_{1 / 2}$-absorption half-life. 


\subsubsection{Tissue Distribution}

Tissue distribution study was done to check the presence of unconjugated magnolol after oral administration of either pure magnolol or mag@Uio-66(Zr) in rats. One-hour post-oral administration of $50 \mathrm{mg} \mathrm{kg}^{-1}$ of magnolol and mag@Uio-66(Zr), principal organs were obtained. No significant differences were observed for the mean magnolol concentration in the brain, liver, and kidneys of all test animals after one hour with p-values of 0.361, 0.299, and 0.051, respectively, as shown in Table 2.

Table 2. Summary of the mean magnolol concentration $(\mu \mathrm{g} / \mathrm{g})$ of magnolol and mag@Uio-66(Zr) in the brains, livers, and kidneys.

\begin{tabular}{cccc}
\hline \multirow{2}{*}{ Test Compound } & \multicolumn{3}{c}{ Organs } \\
\cline { 2 - 4 } & Brain $(\mu \mathrm{g} / \mathrm{g})$ & Liver $(\mu \mathrm{g} / \mathrm{g})$ & Kidneys $(\mu \mathrm{g} / \mathrm{g})$ \\
\hline Magnolol & $0.374 \pm 0.022$ & $0.79 \pm 0.18$ & $3.74 \pm 0.89$ \\
\hline Mag@Uio-66(Zr) & $0.413 \pm 0.034$ & $1.07 \pm 0.19$ & $1.82 \pm 0.21$ \\
\hline
\end{tabular}

$n=3$; data presented as mean \pm S.E.M $(\mu \mathrm{g} / \mathrm{g})$. Organ collected after $1 \mathrm{~h}$ of oral administration of the test compounds.

\section{Discussion}

This is the first study utilizing Zr-based metal organic framework as a drug carrier for magnolol. Uio-66(Zr) (2) exhibited time-dependent loading of magnolol up to $36 \mathrm{~h}$ due to longer exposure of the MOF to magnolol (1), accounting for $72.16 \% w / w(\sim 0.721 \mathrm{mg}$ of magnolol present per milligram of Uio-66(Zr)). However, a drastic decrease in the loading efficiency was observed, suggesting that longer exposure to the nucleophilic hydroxyl group of magnolol affects the integrity of the MOF structure [48]. The high entrapment efficiency of magnolol in the Uio-66( $\mathrm{Zr})$ is mainly attributed to its high BET surface area, pore volume and pore diameter $\left(1156.0643 \mathrm{~m}^{2} / \mathrm{g}, 0.473321 \mathrm{~cm}^{3} / \mathrm{g}\right.$, and $16.377 \AA$, respectively). Magnolol was effectively incorporated into the Uio-66(Zr) framework as the magnolol diameter is $12.99 \AA$ (as calculated, via semi-empirical optimization, using ACD/ChemSketch) compared with the previously obtained pore diameter of Uio-66(Zr) from the nitrogen absorption-desorption analysis $(16.377 \AA)$, thus allowing entry of magnolol. Another key consideration for the incorporation of magnolol is the amphiphilic nature of the internal environment within MOF allowing the incorporation of both hydrophilic and hydrophobic drugs [49]. Possible host-guest interactions include hydrogen bonding and $\pi-\pi$ interactions, as illustrated in Figure 9 [50]. Two hydrogen binding sites are present in the magnolol structure located at the two terminal hydroxyl group attached to the benzene ring. Additionally, the $\pi-\pi$ interactions between magnolol and the organic ligands enable the higher loading efficiency of magnolol in the Uio-66(Zr).

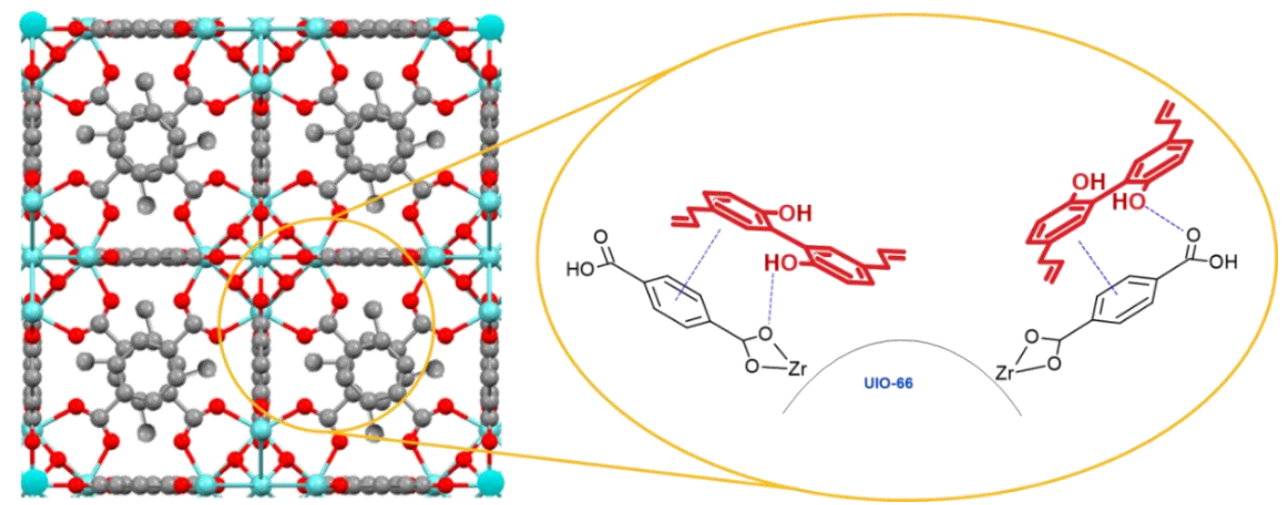

Figure 9. Predicted binding mechanism of magnolol to Uio-66(Zr) [51] showing $\pi-\pi$ interaction and hydrogen bonding. 
Similar findings were noted by previous researches using Uio-66(Zr) as its drug carrier (aspirin [46], ibuprofen [46,52], caffeine [53], and doxorubicin [54]). Additionally, the use of Uio-66(Zr) in entrapping doxorubicin [54], and alendronate [55] produces a 100\% drug loading ( 1mg of drug per milligram of Uio-66(Zr)). These findings support that magnolol being a smaller molecule compared to ibuprofen, caffeine, doxorubicin, and alendronate can be easily incorporated into the Uio-66( $\mathrm{Zr})$ framework. This work presents better drug loading capacity of magnolol into the MOF compared to unfunctionalized and functionalized mesoporous silica (5.5\% and $12.5 \%$, respectively) [14], binary micelle system (SOL-HS15: 4.12\%, and SOL-TPGS:4.03\%) [13], Pluronic micelle system (27.58\%) [12], polyketal microparticles (Mag-PK3: 7.86\% and Mag-PLGA: 6.16\%) [56], and ultrafine fibrous mats (20-30\%) [57] but lower than hydrogel nanoparticles (91.6\%) [15].

The release of magnolol in three different media resulted to $2.47 \% \pm 0.37 \%(\mathrm{PBS} \mathrm{pH} 6.8), 2.89 \pm 0.09 \%$ (PBS pH 7.4), and $4.19 \pm 0.03 \%(0.1 \mathrm{~N} \mathrm{HCl} \mathrm{pH} \mathrm{2)} \mathrm{after} \mathrm{four} \mathrm{hours.} \mathrm{These} \mathrm{data} \mathrm{show} \mathrm{that} \mathrm{Mag@Uio-66(Zr)}$ preparation was $\mathrm{pH}$ dependent. It was noted previously that Uio-66(Zr) when exposed to $0.1 \mathrm{M}$ $\mathrm{HCl}$ resulted in the protonation of the carboxylate groups present in the organic linker (terephthalic acid), suggesting that chloride ions provide charge compensation to the framework. This results to an incomplete reversible structural breakdown due to the four $\mathrm{Zr}-\mathrm{O}$ bonds between each terephthalic acid [58,59]. Degradation of Uio-66(Zr) in PBS pH 7.4 and 6.8 is mainly driven by the presence of a strongly coordinating anion, phosphate ion. The phosphate ion displaces the organic linker attached to the secondary building unit leading to the breakdown of the framework and formation of zirconium phosphate salts $[33,60]$. Moreover, chloride ion is more abundant in the extracellular matrix compared to phosphate. In the study of Rojas and co-workers [46], ibuprofen-Uio-66(Zr) preparation showed a slow release pattern. This slow release pattern is attributed to the hydrophobicity of both host and guest molecules, resulting in slower water diffusion into the pores. This can be correlated with the relatively slow release of magnolol, since magnolol and ibuprofen are similar in structure. The data were fitted into five different mathematical models to determine the mechanism of drug release. Among these models, the Higuchi model best fits all three media with regression factor $\left(\mathrm{r}^{2}\right)$ factors of $0.9343,0.9389$, and 0.9685 for PBS pH 7.4, pH 6.8 and $0.1 \mathrm{M} \mathrm{HCl} \mathrm{pH} \mathrm{2,} \mathrm{respectively.} \mathrm{The} \mathrm{Higuchi} \mathrm{model} \mathrm{describes}$ that the release pattern of magnolol is mainly driven by diffusion-controlled mechanism (dissolutionand diffusion-controlled) $[38,61,62]$. To further illustrate the mechanism of the diffusion-released mechanism, the Korsmeyer-Peppas model was utilized. The kinetic constant (K) for both PBS pH 6.8, and 7.4 are 0.8442 and 0.6919 , respectively, while for $0.1 \mathrm{~N} \mathrm{HCl}$, it is 0.9922 . Due to the nearly spherical shape of Uio-66(Zr), the spherical geometry was utilized to identify the transport mechanism. Both PBS are characterized to show an anomalous transport $(n=0.43-0.85)$ and super case II transport $(n>0.89)$ in the case of $0.1 \mathrm{~N} \mathrm{HCl}$ [63]. Anomalous or non-Fickian transport shown in Figure 10A, describes the mechanism of drug release that is governed by diffusion and swelling in which the rates are comparable. The time-dependent release is mainly dependent on the rearrangement of the polymeric chains and the diffusion process. In comparison with the super case II shown in Figure 10B, tension and breaking of the polymeric chain occurs as the speed of solvent diffusion is greater than the polymeric relaxation, causing an accelerated solvent penetration. This supports the effect of the ionization of the ligand at a lower $\mathrm{pH}$ resulting to breaking of the framework [64]. However, the composition of the release media and actual body fluids differ and greatly affect the drug release kinetics, thus, a direct comparison is not possible [46]. The cumulative amount of magnolol released did not reach more than $90 \%$, probably due to the presence of the drug inside some micropore, covalent and $\pi-\pi$ interactions [35]. 

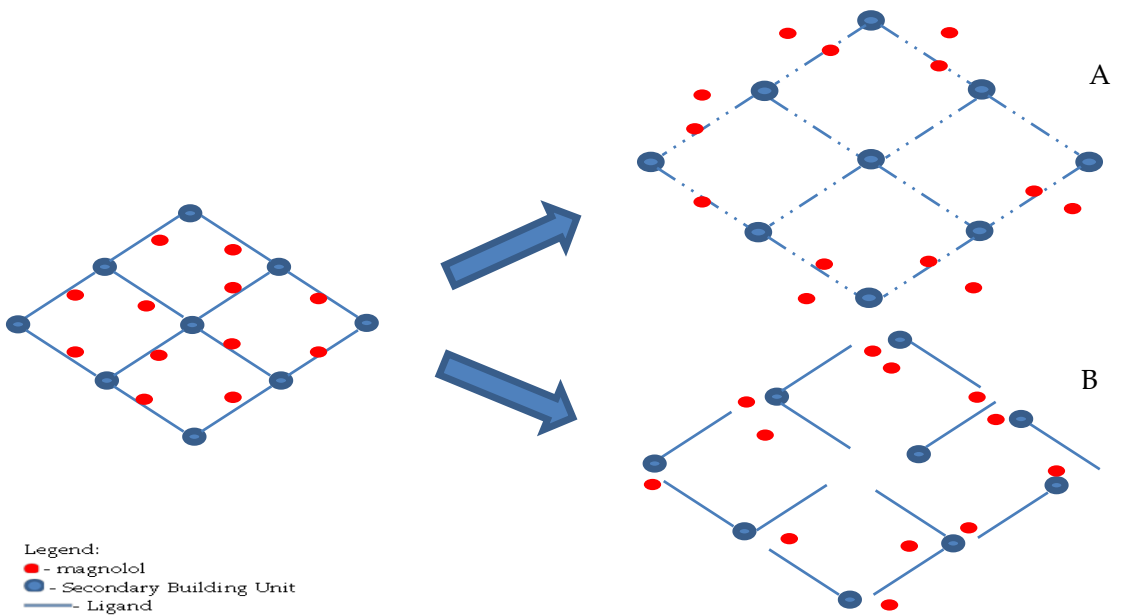

Figure 10. Illustration of the release of magnolol from mag@Uio-66(Zr) depicting (A) swelling and diffusion and (B) tension and breaking.

The two degradation patterns of MOFs were breaking of metal-ligand bonding, leading to the formation of more stable complex or compound compared to the pristine MOF $[65,66]$. MOFs were generally formed from the Lewis acid-base (nucleophile-electrophile) interaction, thereby the presence of a more nucleophilic compound triggers the collapse of the framework as stronger nucleophile tends to bind to the electrophile, forming a more stable compound $[58,67]$. Proteins possess a variety of nucleophilic side chains that can react to the MOF structure, leading to a water-soluble compound [68]. Collapse of the MOF structure leads to the release of the secondary building unit (SBU) that contains the metal ion. These SBUs are characterized to have thermodynamic stability, and mechanical and architectural stability that ensures that the metal ion is strongly bound inside the molecule [69]. Release of $\mathrm{Zr}_{6} \mathrm{O}_{4}(\mathrm{OH})_{4}$ happens upon the degradation of Uio-66( $\left.\mathrm{Zr}\right)$ as this molecule serves as the SBU [58]. Lastly, zirconium has been reported to possess a very low systemic toxicity due to its poor water solubility $[27,70]$.

Along with the $\mathrm{AUC}_{0-720}$ and $\mathrm{AUC}_{0-\infty}$, mag@Uio-66(Zr) showed a significant increase in the maximal time reaching the maximal plasma concentration (Tmax), maximal plasma concentration (Cmax), elimination half-life $\left(\mathrm{T}_{1 / 2}\right)$, and absorption half-life (abs $\mathrm{T}_{1 / 2}$ ) compared to magnolol through the oral route $(p<0.001, p=0.044, p=0.037$, and $p<0.001$, respectively). However, only the Tmax and abs $\mathrm{T}_{1 / 2}$ of mag@Uio-66(Zr) showed a significant increase compared to magnolol through the intraperitoneal route ( $p=0.07$, and $p=0.042$, respectively). The relative bioavailability $\left(\mathrm{F}_{\text {rel }}\right)$ of magnolol was increased using the Uio-66(Zr) as its carrier (0.46) compared to the free magnolol (0.2). This result suggests that the use of Uio-66(Zr) markedly increased the plasma concentration of magnolol in the blood and improved the systemic performance of magnolol, specifically in 2.22-fold $\left(\mathrm{AUC}_{0-720)}\right.$, 2.33-fold $\left(\mathrm{AUC}_{0-\infty}\right)$ and 2.09-fold $\left(\mathrm{F}_{\text {rel }}\right)$ increases. Additionally, the $\mathrm{AUC}_{0-720}$ of the orally administered mag@Uio-66( $\mathrm{Zr})$ is significantly comparable with the AUC of the intraperitoneally administered magnolol and mag@Uio-66(Zr) ( $p=0.73$ and $p=0.304$, respectively). The increased AUC and $\mathrm{F}_{\text {rel }}$ of mag@Uio-66(Zr) is attributed to the slow release of magnolol into the media (as indicated by the longer Tmax, $\mathrm{T}_{1 / 2}$, and abs $\mathrm{T}_{1 / 2}$ ) thereby facilitating good solubility of magnolol and preventing saturation of the media. Another importance in the use of Uio-66(Zr) is its ability in permeating the cells through endocytosis, which enables it to deliver the drug into the blood stream [27]. This would strongly suggest that the rate limiting factor for the use of magnolol can be addressed without compromising the ease of administration. Furthermore, the use of Uio-66( $\mathrm{Zr})$ prolonged the duration of the drug in the blood as indicated by a longer Tmax, $\mathrm{T}_{1 / 2}$, and abs $\mathrm{T}_{1 / 2}$. The Tmax of mag@uio-66(Zr) $(3.26 \mathrm{~h})$ is longer compared to other related drug delivery system of magnolol using Pluronic F127-L61 (0.75 \pm 0.158) [12], SOL-HS15 micellar system $(0.708 \pm 0.188)$ [13], and SOL-TPGS micellar system (0.750 \pm 0.158$)$ [13]. 
Along with the data of the in vitro drug release, this would indicate that the use of Uio-66(Zr) as drug carrier can provide a sustained and controlled release of drugs.

Finally, in agreement with previously mentioned pharmacokinetic parameters, the amount of magnolol detected in the organs (brain, kidney and liver) of the orally administered mag@Uio-66(Zr) were all comparable with the free magnolol. Taking into consideration that the extraction time (60 $\mathrm{min}$ ) was relatively close with the Tmax of magnolol $(55.77 \pm 4.17 \mathrm{~min}$ ) and far from the Tmax of mag@Uio-66(Zr) $(196.97 \pm 17.38 \mathrm{~min})$, this result would support the previous data of AUC and $\mathrm{F}_{\text {rel }}$ regarding the better absorption of magnolol using Uio-66(Zr).

\section{Conclusions}

The study describes the utilization of MOF as drug carrier for magnolol. Experimental outcomes suggested that MOF can be used as carrier for molecules due to their relative high surface area. The study suggests that mag@Uio-66(Zr) possesses a relatively slow release pattern but this should be confirmed with the complete release profile of magnolol. The bioavailability of magnolol was increased using Uio-66(Zr) as its drug carrier without compromising the safety of magnolol. Systemic performance was enhanced based on the increased $\mathrm{AUC}_{0-720}, \mathrm{AUC}_{0-\infty}$, and $\left(\mathrm{F}_{\text {rel }}\right)$ for magnolol upon utilization of Uio-66(Zr). With the data from the in vitro drug release and the prolongation of the Tmax, this would suggest that the use of Uio-66(Zr) as drug carrier can lead to a prolonged released of magnolol. Metal organic framework serves as a new avenue for a drug delivery system that is nontoxic and effectively delivers poorly soluble drugs into the blood.

Supplementary Materials: Summary of the drug release kinetic models for the in vitro drug release study. The following are available online at http://www.mdpi.com/1999-4923/12/5/437/s1, Table S1: Summary of Kinetic model constants for the three release media of Uio-66(Zr) at $4 \mathrm{~h}$.

Author Contributions: The author contributions for this paper include conceptualization, and methodology J.H.S., M.J.-A.T.C., T.-T.L., C.H.L., and O.B.V.; formal analysis, J.H.S., M.T.J.Q., M.J.-A.T.C., T.-T.L., C.-H.L., and O.B.V.; resources, A.P.G.M., Y.-M.W., T.-T.L., C.-H.L., and O.B.V.; data curation, J.H.S., M.T.J.Q., M.J.-A.T.C., T.-T.L., C.-H.L., and O.B.V.; visualization-J.H.S., M.T.J.Q., A.P.G.M., and O.B.V.; writing-original draft preparation, J.H.S.; writing-review and editing, M.T.J.Q., A.P.G.M., M.J.-A.T.C., T.-T.L., C.-H.L., and O.B.V.; supervision, M.J.-A.T.C., Y.-M.W., T.-T.L., C.-H.L., and O.B.V.; project administration, M.J.-A.T.C., and O.B.V.; funding acquisition, J.H.S. All authors have read and agreed to the published version of the manuscript.

Funding: This research received no external funding.

Acknowledgments: The Accelerated Science and Technology, Human Research Development Program of the Science Education Institute-Department of Science and Technology, Philippines for the graduate scholarship awarded to J.H.S. The guidance and help of Stephen Lirio. The Laboratory mates from Chung Yuan Christian University, namely Pamela Berilyn So, Li-Hao Liu, Yu-Ching Kuo, Fang-Yu Li, Zheng-Yu Yang, Jin-Cheng Huang, Yu-Feng Hong, Bing-Han Li, and Bo-Siang Tang under Professor Chia-Her Lin and from National Tsing-Hua University, namely Cheng-Ru Wu, under Professor Tsai-Te Lu.

Conflicts of Interest: The authors declare no conflict of interest.

\section{References}

1. Gupta, S.; Kesarla, R.; Omri, A. Formulation strategies to improve the bioavailability of poorly absorbed drugs with special emphasis on self-emulsifying systems. ISRN Pharm. 2013, 2013, 1-16. [CrossRef]

2. $\mathrm{Hu}, \mathrm{M} . ; \mathrm{Li}, \mathrm{X}$. Series in drug discovery and development. In Oral Bioavailability: Basic Principles, Advanced Concepts, and Applications; John Wiley \& Sons: Hoboken, NJ, USA, 2011; ISBN 978-0-470-26099-9.

3. Gao, S.; Hu, M. Bioavailability challenges associated with development of anti-cancer phenolics. Mini Rev. Med. Chem. 2010, 10, 550-567. [CrossRef]

4. Ko, C.H.; Chen, H.H.; Lin, Y.R.; Chan, M.H. Inhibition of smooth muscle contraction by magnolol and honokiol in porcine trachea. Planta Med. 2003, 69, 532-536. [CrossRef] [PubMed]

5. Syu, W.-J.; Shen, C.-C.; Lu, J.-J.; Lee, G.-H.; Sun, C.-M. Antimicrobial and cytotoxic activities of neolignans from Magnolia officinalis. Chem. Biodivers. 2004, 1, 530-537. [CrossRef] [PubMed] 
6. Homma, M.; Minami, M.; Taniguchi, C.; Oka, K.; Morita, S.; Niitsuma, T.; Hayashi, T. Inhibitory effects of lignans and flavonoids in saiboku-to, a herbal medicine for bronchial asthma, on the release of leukotrienes from human polymorphonuclear leukocytes. Planta Med. 2000, 66, 88-91. [CrossRef]

7. Haraguchi, H.; Ishikawa, H.; Shirataki, N.; Fukuda, A. Antiperoxidative activity of neolignans from Magnolia obovata. J. Pharm. Pharmacol. 1997, 49, 209-212. [CrossRef] [PubMed]

8. Chen, Y.; Huang, K.; Ding, X.; Tang, H.; Xu, Z. Magnolol inhibits growth and induces apoptosis in esophagus cancer KYSE-150 cell lines via the MAP kinase pathway. J. Thorac. Dis. 2019, 11, 3030-3038. [CrossRef] [PubMed]

9. Lee, J.; Jung, E.; Park, J.; Jung, K.; Lee, S.; Hong, S.; Park, J.; Park, E.; Kim, J.; Park, S.; et al. Anti-inflammatory effects of magnolol and honokiol are mediated through inhibition of the downstream pathway of MEKK-1 in NF-кB activation signaling. Planta Med. 2005, 71, 338-343. [CrossRef] [PubMed]

10. Tsai, T.H.; Chou, C.J.; Lee, T.F.; Wang, L.C.H.; Chen, C.F. Pharmacokinetic and pharmacodynamic studies of magnolol after oral administration in rats. Pharm. Sci. 1996, 2, 191-193. [CrossRef]

11. Zhang, J.; Chen, Z.; Huang, X.; Shi, W.; Zhang, R.; Chen, M.; Huang, H.; Wu, L. Insights on the multifunctional activities of magnolol. BioMed Res. Int. 2019, 2019, 1847130. [CrossRef]

12. Shen, H.; Liu, S.; Ding, P.; Wang, L.; Ju, J.; Liang, G. Enhancement of oral bioavailability of magnolol by encapsulation in mixed micelles containing Pluronic F127 and L61. J. Pharm. Pharmacol. 2018, 70, 498-506. [CrossRef] [PubMed]

13. Ding, P.; Shen, H.; Wang, J.; Ju, J. Improved oral bioavailability of magnolol by using a binary mixed micelle system. Artif. Cells Nanomed. Biotechnol. 2018, 46, 668-674. [CrossRef] [PubMed]

14. Stefanache, A.; Ignat, M.; Peptu, C.; Diaconu, A.; Stoleriu, I.; Ochiuz, L. Development of a prolonged-release drug delivery system with magnolol loaded in amino-functionalized Mesoporous Silica. Appl. Sci. 2017, 7, 237. [CrossRef]

15. Wang, Y.J.; Chien, Y.C.; Wu, C.H.; Liu, D.M. Magnolol-loaded core-shell hydrogel nanoparticles: Drug release, intracellular uptake, and controlled cytotoxicity for the inhibition of migration of vascular smooth muscle cells. Mol. Pharm. 2011, 8, 2339-2349. [CrossRef] [PubMed]

16. Lee, C.-W.; Hu, S.C.-S.; Yen, F.-L.; Hsu, L.-F.; Lee, I.-T.; Lin, Z.-C.; Tsai, M.-H.; Huang, C.-L.; Liang, C.-J.; Chiang, Y.-C. Magnolol nanoparticles exhibit improved water solubility and suppress TNF- $\alpha$-induced VCAM-1 expression in endothelial cells. J. Biomed. Nanotechnol. 2017, 13, 255-268. [CrossRef]

17. Lin, S.P.; Hou, Y.C.; Liao, T.Y.; Tsai, S.Y. Enhancing the bioavailability of magnolol in rabbits using melting solid dispersion with polyvinylpyrrolidone. Drug Dev. Ind. Pharm. 2014, 40, 330-337. [CrossRef]

18. Wang, W.; Cui, C.; Li, M.; Zhang, Z.; Lv, H. Study of a novel disintegrable oleanolic acid-polyvinylpolypyrrolidone solid dispersion. Drug Dev. Ind. Pharm. 2017, 43, 1178-1185. [CrossRef]

19. Chen, C.Y.-C.; Wu, C.-H. Magnolol encapsulated by liposome in inhibiting smooth muscle cell proliferation. J. Chin. Chem. Soc. 2008, 55, 517-521. [CrossRef]

20. Gangu, K.K.; Maddila, S.; Mukkamala, S.B.; Jonnalagadda, S.B. A review on contemporary metal-organic framework materials. Inorg. Chim. Acta 2016, 446, 61-74. [CrossRef]

21. Janiak, C.; Vieth, J.K. MOFs, MILs and more: Concepts, properties and applications for porous coordination networks (PCNs). New J. Chem. 2010, 34, 2366. [CrossRef]

22. Seth, S.; Matzger, A.J. Metal-organic frameworks: Examples, counterexamples, and an actionable definition. Cryst. Growth Des. 2017, 17, 4043-4048. [CrossRef]

23. Wang, L.; Zheng, M.; Xie, Z. Nanoscale metal-organic frameworks for drug delivery: A conventional platform with new promise. J. Mater. Chem. B 2018, 6, 707-717. [CrossRef] [PubMed]

24. Shearer, G.C.; Chavan, S.; Bordiga, S.; Svelle, S.; Olsbye, U.; Lillerud, K.P. Defect engineering: Tuning the porosity and composition of the metal-organic framework UiO-66 via modulated synthesis. Chem. Mater. 2016, 28, 3749-3761. [CrossRef]

25. Cochran, K.W.; Doull, J.; Mazur, M.; Dubois, K.P. Acute toxicity of zirconium, columbium, strontium, lanthanum, cesium, tantalum and yttrium. Arch Ind. Hyg. Occup. Med. 1950, 1, 637-650. [PubMed]

26. Ghosh, S.; Sharma, A.; Talukder, G. Zirconium: An abnormal trace element in biology. Biol. Trace Elem. Res. 1992, 35, 247-271. [CrossRef]

27. Orellana-Tavra, C.; Mercado, S.A.; Fairen-Jimenez, D. Endocytosis mechanism of nano metal-organic frameworks for drug delivery. Adv. Healthc. Mater. 2016, 5, 2261-2270. [CrossRef] 
28. Abánades-Lázaro, I.; Wells, C.J.R.; Forgan, R.S. Multivariate modulation of the Zr MOF UiO-66 for defect-controlled combination anticancer drug delivery. Angew. Chem. Int. Ed. 2020. [CrossRef]

29. Dong, H.; Yang, G.; Zhang, X.; Meng, X.; Sheng, J.; Sun, X.; Feng, Y.; Zhang, F. Folic acid functionalized zirconium-based metal-organic frameworks as drug carriers for active tumor-targeted drug delivery. Chem. Eur. J. 2018, 24, 17148-17154. [CrossRef]

30. Li, Z.; Zhao, S.; Wang, H.; Peng, Y.; Tan, Z.; Tang, B. Functional groups influence and mechanism research of UiO-66-type metal-organic frameworks for ketoprofen delivery. Colloids Surf. B Biointerfaces 2019, 178, 1-7. [CrossRef]

31. Nasrabadi, M.; Ghasemzadeh, M.A.; Zand Monfared, M.R. The preparation and characterization of UiO-66 metal-organic frameworks for the delivery of the drug ciprofloxacin and an evaluation of their antibacterial activities. New J. Chem. 2019, 43, 16033-16040. [CrossRef]

32. Ahmed, I.; Tong, M.; Jun, J.W.; Zhong, C.; Jhung, S.H. Adsorption of nitrogen-containing compounds from model fuel over sulfonated metal-organic framework: Contribution of hydrogen-bonding and acid-base interactions in adsorption. J. Phys. Chem. C 2016, 120, 407-415. [CrossRef]

33. Bellido, E.; Hidalgo, T.; Lozano, M.V.; Guillevic, M.; Simón-Vázquez, R.; Santander-Ortega, M.J.; González-Fernández, Á.; Serre, C.; Alonso, M.J.; Horcajada, P. Heparin-engineered mesoporous iron metal-organic framework nanoparticles: Toward stealth drug nanocarriers. Adv. Healthc. Mater. 2015, 4, 1246-1257. [CrossRef] [PubMed]

34. Singco, B.; Liu, L.-H.; Chen, Y.-T.; Shih, Y.-H.; Huang, H.-Y.; Lin, C.-H. Approaches to drug delivery: Confinement of aspirin in MIL-100 (Fe) and aspirin in the de novo synthesis of metal-organic frameworks. Microporous Mesoporous Mater. 2016, 223, 254-260. [CrossRef]

35. Al Haydar, M.; Abid, H.; Sunderland, B.; Wang, S. Metal organic frameworks as a drug delivery system for flurbiprofen. Drug Des. Dev. Ther. 2017, 11, 2685-2695. [CrossRef] [PubMed]

36. Chen, B.; Wang, X.; Zhang, Q.; Xi, X.; Cai, J.; Qi, H.; Shi, S.; Wang, J.; Yuan, D.; Fang, M. Synthesis and characterization of the interpenetrated MOF-5. J. Mater. Chem. 2010, 20, 3758. [CrossRef]

37. Danhier, F.; Lecouturier, N.; Vroman, B.; Jérôme, C.; Marchand-Brynaert, J.; Feron, O.; Préat, V. Paclitaxel-loaded PEGylated PLGA-based nanoparticles: In vitro and in vivo evaluation. J. Control. Release 2009, 133, 11-17. [CrossRef]

38. Baishya, H. Application of mathematical models in drug release kinetics of carbidopa and levodopa ER tablets. J. Dev. Drugs 2017, 6. [CrossRef]

39. Organization for Economic Cooperation and Development. Test no. 425: Acute oral toxicity: Up-and-down procedure. In OECD Guidelines for the Testing of Chemicals, 4th ed.; OECD Publishing: Paris, France, 2008; ISBN 9789264071049.

40. Higashi, Y. Simultaneous analysis of honokiol and magnolol in rat serum by HPLC with fluorescence detection after solid-phase extraction for pharmacokinetic studies. Austin J. Anal. Pharm. Chem. 2015, 2, 1-5.

41. Kotani, A.; Kojima, S.; Hakamata, H.; Jin, D.; Kusu, F. Determination of honokiol and magnolol by micro HPLC with electrochemical detection and its application to the distribution analysis in branches and leaves of Magnolia obovata. Chem. Pharm. Bull. 2005, 53, 319-322. [CrossRef]

42. Lin, S.-P.; Tsai, S.-Y.; Chao, L.P.-D.; Chen, Y.-C.; Hou, Y.-C. Pharmacokinetics, bioavailability, and tissue distribution of magnolol following single and repeated dosing of magnolol to rats. Planta Med 2011, 77, 1800-1805. [CrossRef]

43. Kurisingal, J.F.; Babu, R.; Kim, S.-H.; Li, Y.X.; Chang, J.-S.; Cho, S.J.; Park, D.-W. Microwave-induced synthesis of a bimetallic charge-transfer metal organic framework: A promising host for the chemical fixation of $\mathrm{CO}_{2}$. Catal. Sci. Technol. 2018, 8, 591-600. [CrossRef]

44. Miri, B.; Motakef-Kazemi, N.; Shojaosadati, S.A.; Morsali, A. Application of a nanoporous metal organic framework based on iron carboxylate as drug delivery system. Iran J. Pharm. Res. 2018, 17, 1164-1171. [PubMed]

45. Li, Z.; Peng, Y.; Xia, X.; Cao, Z.; Deng, Y.; Tang, B. Sr/PTA metal organic framework as a drug delivery system for osteoarthritis treatment. Sci. Rep. 2019, 9, 17570. [CrossRef] [PubMed]

46. Rojas, S.; Colinet, I.; Cunha, D.; Hidalgo, T.; Salles, F.; Serre, C.; Guillou, N.; Horcajada, P. Toward understanding drug incorporation and delivery from biocompatible metal-organic frameworks in view of cutaneous administration. ACS Omega 2018, 3, 2994-3003. [CrossRef] [PubMed] 
47. Abrams, D.B.; Turner, J.R.; Baumann, L.C.; Karel, A.; Collins, S.E.; Witkiewitz, K.; Fulmer, T.; Tanenbaum, M.L.; Commissariat, P.; Kupperman, E.; et al. Area under the curve (AUC). In Encyclopedia of Behavioral Medicine; Gellman, M.D., Turner, J.R., Eds.; Springer: New York, NY, USA, 2013; pp. 125-126, ISBN 978-1-4419-1004-2.

48. Isaeva, V.I.; Kustov, L.M. The application of metal-organic frameworks in catalysis (Review). Pet. Chem. 2010, 50, 167-180. [CrossRef]

49. Giménez-Marqués, M.; Hidalgo, T.; Serre, C.; Horcajada, P. Nanostructured metal-organic frameworks and their bio-related applications. Coord. Chem. Rev. 2016, 307, 342-360. [CrossRef]

50. Wittmann, T.; Tschense, C.B.L.; Zappe, L.; Koschnick, C.; Siegel, R.; Stäglich, R.; Lotsch, B.V.; Senker, J. Selective host-guest interactions in metal-organic frameworks via multiple hydrogen bond donor-acceptor recognition sites. J. Mater. Chem. A 2019, 7, 10379-10388. [CrossRef]

51. Liu, J.; Canfield, N.; Liu, W. Preparation and characterization of a hydrophobic metal-organic framework membrane supported on a thin porous metal sheet. Ind. Eng. Chem. Res. 2016, 55, 3823-3832. [CrossRef]

52. Sun, W.; Li, H.; Li, H.; Li, S.; Cao, X. Adsorption mechanisms of ibuprofen and naproxen to UiO-66 and UiO-66-NH2: Batch experiment and DFT calculation. Chem. Eng. J. 2019, 360, 645-653. [CrossRef]

53. Cunha, D.; Ben Yahia, M.; Hall, S.; Miller, S.R.; Chevreau, H.; Elkaïm, E.; Maurin, G.; Horcajada, P.; Serre, C. Rationale of drug encapsulation and release from biocompatible porous metal-organic frameworks. Chem. Mater. 2013, 25, 2767-2776. [CrossRef]

54. Chen, D.; Yang, D.; Dougherty, C.A.; Lu, W.; Wu, H.; He, X.; Cai, T.; van Dort, M.E.; Ross, B.D.; Hong, H. In vivo targeting and positron emission tomography imaging of tumor with intrinsically radioactive metal-organic frameworks nanomaterials. ACS Nano 2017, 11, 4315-4327. [CrossRef] [PubMed]

55. Zhu, X.; Gu, J.; Wang, Y.; Li, B.; Li, Y.; Zhao, W.; Shi, J. Inherent anchorages in UiO-66 nanoparticles for efficient capture of alendronate and its mediated release. Chem. Commun. 2014, 50, 8779-8782. [CrossRef] [PubMed]

56. Tsai, T.; Kao, C.-Y.; Chou, C.-L.; Liu, L.-C.; Chou, T.-C. Protective effect of magnolol-loaded polyketal microparticles on lipopolysaccharide-induced acute lung injury in rats. J. Microencapsul. 2016, 33, 401-411. [CrossRef] [PubMed]

57. Hao, W.; Song, H.; Cui, Y.; Deng, Y.; Chen, X. Magnolol entrapped ultra-fine fibrous mats electrospun from poly (ethylene glycol)-b-poly (L-lactide) and in vitro release. Chin. J. Polym. Sci. 2011, 29, 173-179. [CrossRef]

58. De Coste, J.B.; Peterson, G.W.; Jasuja, H.; Glover, T.G.; Huang, Y.; Walton, K.S. Stability and degradation mechanisms of metal-organic frameworks containing the $\mathrm{Zr} 6 \mathrm{O} 4(\mathrm{OH}) 4$ secondary building unit. J. Mater. Chem. A 2013, 1, 5642. [CrossRef]

59. Sun, C.-Y.; Qin, C.; Wang, X.-L.; Yang, G.-S.; Shao, K.-Z.; Lan, Y.-Q.; Su, Z.-M.; Huang, P.; Wang, C.-G.; Wang, E.-B. Zeolitic imidazolate framework-8 as efficient $\mathrm{pH}$-sensitive drug delivery vehicle. Dalton Trans. 2012, 41, 6906. [CrossRef]

60. Orellana-Tavra, C.; Marshall, R.J.; Baxter, E.F.; Lázaro, I.A.; Tao, A.; Cheetham, A.K.; Forgan, R.S.; Fairen-Jimenez, D. Drug delivery and controlled release from biocompatible metal-organic frameworks using mechanical amorphization. J. Mater. Chem. B 2016, 4, 7697-7707. [CrossRef]

61. Jain, A.; Thakur, K.; Kush, P.; Jain, U.K. Docetaxel loaded chitosan nanoparticles: Formulation, characterization and cytotoxicity studies. Int. J. Biol. Macromol. 2014, 69, 546-553. [CrossRef]

62. Danyuo, Y.; Ani, C.J.; Salifu, A.A.; Obayemi, J.D.; Dozie-Nwachukwu, S.; Obanawu, V.O.; Akpan, U.M.; Odusanya, O.S.; Abade-Abugre, M.; McBagonluri, F.; et al. Anomalous release kinetics of prodigiosin from poly-N-isopropyl-acrylamid based hydrogels for the treatment of triple negative breast cancer. Sci. Rep. 2019, 9, 3862. [CrossRef]

63. Peppas, N.A. Analysis of fickian and non-fickian drug release from polymers. Pharm. Acta Helv. 1985, 60, 110-111.

64. Klech, C.M.; Simonelli, A.P. Examination of the moving boundaries associated with non-fickian water swelling of glassy gelatin beads: Effect of solution pH. J. Membr. Sci. 1989, 43, 87-101. [CrossRef]

65. Low, J.J.; Benin, A.I.; Jakubczak, P.; Abrahamian, J.F.; Faheem, S.A.; Willis, R.R. Virtual high throughput screening confirmed experimentally: Porous coordination polymer hydration. J. Am. Chem. Soc. 2009, 131, 15834-15842. [CrossRef] [PubMed]

66. Antwi-Baah, R.; Liu, H. Recent hydrophobic metal-organic frameworks and their applications. Materials 2018, 11, 2250. [CrossRef] [PubMed] 
67. Harvey, J.A.; Pearce, C.J.; Hall, M.G.; Bruni, E.J.; De Coste, J.B.; Sava-Gallis, D.F. Insights into the solvent-assisted degradation of organophosphorus compounds by a Zr-based metal-organic framework. Dalton Trans. 2019, 48, 16153-16157. [CrossRef] [PubMed]

68. Brotzel, F.; Mayr, H. Nucleophilicities of amino acids and peptides. Org. Biomol. Chem. 2007, 5, 3814. [CrossRef]

69. Kalmutzki, M.J.; Hanikel, N.; Yaghi, O.M. Secondary building units as the turning point in the development of the reticular chemistry of MOFs. Sci. Adv. 2018, 4, 9180. [CrossRef]

70. Schaate, A.; Roy, P.; Godt, A.; Lippke, J.; Waltz, F.; Wiebcke, M.; Behrens, P. Modulated synthesis of Zr-based metal-organic frameworks: From nano to single crystals. Chemistry 2011, 17, 6643-6651. [CrossRef]

(C) 2020 by the authors. Licensee MDPI, Basel, Switzerland. This article is an open access article distributed under the terms and conditions of the Creative Commons Attribution (CC BY) license (http://creativecommons.org/licenses/by/4.0/). 